\title{
Global Value Chain: The Effects of Trade Mechanism on Energy Efficiency using Simultaneous Equation: Evidence from Asian Countries within Belt and Road
}

\author{
Mensah Patience Acquah \\ School of Finance and Economic, Jiangsu University \\ Zhenjiang, P.R. China. \\ Mandella Osei Assibey Bonsu \\ Madiba Group Ghana, Mallam, Accra, Ghana \\ Rosemond Atampokah \\ School of Management, Jiangsu University \\ Zhenjiang, 212013, P.R. China
}

Received: April 18, 2021 Accepted: June 21, $2021 \quad$ Published: July 22, 2021

doi:10.5296/ber.v11i3.18877

URL: https://doi.org/10.5296/ber.v11i3.18877

\begin{abstract}
Long-term economic development is thought to necessitate the use of energy. To sustain steady economic growth, economies have increased their dependence on energy sources, tightened restrictions, and put pressure on energy supplies. Our paper employed simultaneous equations with GMM and SBM model to examine the impact of trade mechanism on energy efficiency of Asian countries within the Belt and Road Countries. We find significant increase in energy efficiency. After controlling the heterogeneous effects, the magnitude impact of the coefficient was noticeably which approves that the heterogeneity of countries and years influence the empirical findings of the model. Further, we find and validates that trade in the GVC mechanism helps to promote energy efficiency. Energy efficiency could be greatly promoted by emphasizing its significance in the age of GVC. Several policy recommendations support the findings
\end{abstract}

Keywords: Value chain, Trade, Value added trade, Asia, SBM model 


\section{Introduction}

Energy is seen as a necessity for long-term economic growth. Economies have expanded their reliance on energy sources to maintain steady economic growth, tighten limitations, and put pressure on energy supply (Xu and Lin, 2018). Global energy statistics for 2019 show a significant increase in global energy consumption, owing mostly to the growth of the developing world, which includes countries along the Belt and Road in Asia, including leaders like China and India. The United States was the world's second-largest energy user in 2018, with 2.3 Health and achieving, up 3.5 percent from 2017. In 2018, demand for coal, the second-largest energy source, climbed by 1.4 percent, while demand for natural gas increased by more than 5\%, the most in more than 30 years (World Energy Outlook, 2019). In a nutshell, the energy demand of each source is increasing.

Nonetheless, excessive energy consumption has two consequences: one is energy scarcity, and the other is that most energy sources, such as coal and oil, emit significant quantities of $\mathrm{CO} 2$. As a result, rising energy demands and declining energy supplies raise significant challenges for policymakers when contemplating the environmental implications of energy policy formulation. Energy efficiency and productivity are two of the most cost-effective strategies to address climate change and cut emissions. Improving energy infrastructure as part of an energy-efficiency pledge would result in significant resource savings, lower production costs, and market competitiveness (Oda et al., 2012).

One of the most important pathways for cross-national technical interchange is international trade, and technological innovation is a vital component of increasing energy efficiency. Trade is a key driver of energy efficiency promotion, according to an empirical study by Boqiang and Hongxun (2015). International exchange allows goods produced in one nation to be consumed or processed in another. As a result, researchers come to the conclusion that trade is a process that reduces carbon emissions by exposing people to environmentally friendly technologies (Yasmeen et al., 2018; Yao et al., 2019; Yasmeen et al., 2019; Shah et al., 2019). Furthermore, by incorporating advanced energy-saving technologies, developing countries will improve the performance of their manufacturing processes (Yao et al., 2020). International trade enables developing countries to import energy-saving technology from developed countries that requires less energy and generates more output. Furthermore, trade has a significant catalytic effect on technological growth and reduces the trade market's energy intensity, which is not by chance. China, as the world's largest exporter, is an excellent example of a country that has benefited from international trade. International commerce, in general, works to improve the industrial sector's energy efficiency, both actively and passively (Zhao and Lin, 2019).

In the one hand, trade allows businesses to come up with fresh and innovative ideas, but on the other, it demands high-quality goods that meet global consumer expectations. Despite the fact that the connection between energy efficiency and trade is a major source of concern, it has yet to be fully evaluated. The current study backs up this assumption by focusing on VAT rather than total trade in order to throw light on trade and energy efficiency in the global value chain. As a result, there is currently a GVC for product manufacturing in the country. 
Countries with a lot of capital and technology have a lot of added value in the GVC.

Even so, countries with a high GVC are more energy efficient and can produce products with less inputs of energy, resulting in lower emissions. As a result, we calculate the impact of VAT on energy efficiency based on the findings of the study (Yao et al., 2020). Furthermore, there is an important distinction to be made between trade openness and VAT, which is often ignored in current literature. To our knowledge, only the work of Yao (202) estimate VAT rather than trade openness with the majority of studies are based on trade openness.

To calculate the energy efficiency of the sampled countries, we used a simultaneous equation with GMM and SBM model proposed by Huang et al. (2014). We discover a big boost in energy efficiency. The magnitude impact of the coefficient was noticeably reduced after adjusting for heterogeneous effects, indicating that the heterogeneity of countries and years influences the empirical results of the model. Further, we find and validates that trade in the GVC mechanism helps to promote energy efficiency.

Our paper contributes to the extant literature in twofold: First, our paper adds to the ongoing debate about how Global Value Chain impacts energy efficiency by presenting new evidence from Asian culture where China and India are leaders of trade. Second, little empirical research has been done on GVC mechanism helps to promote energy efficiency. However, previous studies (Oda et al., 2012; Moreau and Vuille (2018; Meng et al. (2015), and Zhang et al. (2017) used trade and export as measure of trade mechanism but this used value added trade as a measure for trade mechanisms (Yao et al., 2020).

The following constructs are used to present the rest of the paper. The second section examines the relevant literature. The technique is discussed in Section 3. Section 4 presents the results, shows the empirical findings, and discusses them. The analysis comes to a close in the final segment.

\section{Brief Literature Review}

This paper discusses the viewpoints on Energy Efficiency Trade Nexus. Numerous researches have been conducted on the relationship between commerce and oil. From 1976 to 2014, Pan et al. (2019) did a time series study in Bangladesh. They came to the conclusion that increased energy intensity is influenced by trade openness, economic growth, and technical innovation. They also came to the conclusion that trade boosts economic activity and aids countries in properly using capital. Moreau and Vuille (2018) find that energy efficiency in Switzerland is largely offset by economic growth by focusing on decoupling energy use in growth and embodied energy in trade, Embedded energy in exchange, on the other hand, suggests that decoupling is more virtual than actual. The input-output approach was utilized by Li et al. (2014) to investigate China's trade settings, and they discovered that structural changes in foreign trade do not help China save resources. Farrow et al. (2018), Meng et al. (2015), and Zhang et al. (2015) investigated the relationship between export structure and energy restrictions (2017).

From the perspective of industrial technologies, several studies have looked at the relationship between energy efficiency and international trade. Manufacturing technology, 
according to Lin et al., (2012), has a substantial impact on energy efficiency. According to Dawei et al., (2010), import trade is more favourable to obtaining advanced foreign technology than export commerce, and hence the energization of the economy.

Boqiang and Hongxun (2015) looked at the Chinese sector in depth to discover how trade affects energy efficiency and, as a result, environmental quality. They claimed that trade appears to promote energy efficiency and environmental efficiency since trade and energy conservation have a favorable association.

Roy and Yasar (2015) reported similar findings, claiming that trade increases energy efficiency. Though, in the case of China, some studies on energy efficiency and international trade have been performed, which can be divided into three categories (Zhang et al., 2017). In the first group, energy intensity is utilized to approximate the relationship between energy efficiency and international trade (Dan, 2002). Second-class investigates the link between energy efficiency and foreign trade, taking into account the overall energy efficiency factor (Gao and Zhou, 2010). Energy intensity is used in the first group to approximate the relationship between energy efficiency and foreign trade (Dan, 2002). Second-class investigates the link between energy efficiency and foreign trade, taking into account the overall energy efficiency factor (Gao and Zhou, 2010). Increased industrial structure, increased rivalry, and technical developments all lead to increased energy efficiency, according to the research. Furthermore, commerce and ene may have a two-way causal link. There is still opportunity for research in this field due to the scarcity of literature on trade and energy efficiency nexuses.

\section{Data and Variables, and Measurement}

\subsection{Measuring of the Energy Efficiency}

DEA is a well-known linear programming technique for determining the relative efficiency of a group of homogeneous decision-making units (DMUs) using a variety of inputs and outputs, independent of the DMUs' internal structure (Zhu, et al. 2020). Various radial and non-radial models have also been used to assess performance in various industries and government organizations. In contrast to two traditional models (CCR and BCC) developed by others, Tone (2001) introduces a non-radial, slack-based model (SBM) that uses slacks of inputs and outputs to build the efficiency frontier (Charnes et al., 1978; Banker et al., 1984). Neglecting unsatisfactory performance during the manufacturing process, on the other hand, results in a less efficient production step. To address this issue, Tone (2003) developed an enhanced SBM model, which could help to fix the unsatisfactory efficiency evaluation results. Tone also created a model that could distinguish between efficient and inefficient DMUs, while numerous DMUs had the same efficiency score in traditional DEA models. The S-SBM model ranks successful DMUs using a super-efficiency model. Super SBM, despite its many advantages, is unable to cope with the bad results. As a consequence, we measure each country's energy efficiency using Huang et al. (2014)'s improved super-SBM model, which can recognize successful DMUs in the presence of undesirable output.

$$
X=\left[x_{1} \ldots x_{\mathrm{N}}\right] \mathrm{ER}^{\mathrm{MN}}, \mathrm{Y}^{\mathrm{g}}=\left[\mathrm{y}^{\mathrm{g}}, \ldots, \mathrm{y}^{\mathrm{g}}\right] \mathrm{ER}^{\mathrm{S}, \mathrm{XN}}, \text { and } \mathrm{y}^{\mathrm{b}}=\left[\mathrm{y}_{\mathrm{i}}^{\mathrm{b}}, \ldots \mathrm{y}^{\mathrm{b}}{ }_{\mathrm{n}}\right]
$$




\section{Macrothink}

$\mathrm{ER}^{\mathrm{S} 2 \mathrm{~N}}$ and $\lambda$ as weighting vector, the research assumes that $\mathrm{X}>0, \mathrm{Y}^{\mathrm{g}}>0, \mathrm{Y}^{\mathrm{g}}>0, \mathrm{Y}^{\mathrm{b}}>0$, the production possibilities set as follows:

$$
\mathrm{P}=\left\{\left(x, y^{g}\right) / x \geq X \lambda, y^{g} \leq y^{g} \lambda, y^{g} \geq y^{b} \lambda \geq 0\right\}
$$

US-SMB is the combination of S-SMB and U-SBM models which can handle the undesirable output (cite). We can compose equation (3) using the input-output

$$
\begin{gathered}
{\left[Z^{s s}+Z^{s r}+Z^{s t}\right]+\left[Y^{s s}+Y^{s r}+Y^{s t}\right]=\left[\mathrm{X}^{\mathrm{s}}\right]} \\
{\left[Z^{r s}+Z^{r r}+Z^{r t}\right]+\left[Y^{r s}+Y^{r r}+Y^{r t}\right]=\left[\mathrm{X}^{\mathrm{r}}\right]} \\
{\left[Z^{t s}+Z^{t r}+Z^{t t}\right]+\left[Y^{t s}+Y^{t r}+Y^{t t}\right]=\left[\mathrm{X}^{\mathrm{t}}\right]}
\end{gathered}
$$

Where, $A=Z$, so we can get

$$
\begin{array}{rrr}
{\left[A^{s s}+A^{s r}+A^{s t}\right]} & {\left[Y^{s s}+Y^{s r}+Y^{s t}\right]=X^{s}} \\
{\left[A^{r s}+A^{r r}+A^{r t}\right]} & & {\left[Y^{r s}+Y^{r r}+Y^{r t}\right]=X^{r}} \\
{\left[A^{t s}+A^{t r}+A^{t t}\right]} & {\left[Y^{t s}+Y^{t r}+Y^{t t}\right]=} & X^{t}
\end{array}
$$

We can adjust equation (4), and can calculate the output formular as follows:

$$
\begin{aligned}
& \mathrm{X}^{\mathrm{s}} \quad \mathrm{B}^{\mathrm{ss}} \quad \mathrm{B}^{\mathrm{sr}} \quad \mathrm{B}^{\mathrm{st}}\left[\mathrm{Y}^{\mathrm{ss}}\right] \\
& \mathrm{X}^{\mathrm{r}}=\mathrm{Brs} \quad \mathrm{B}^{\mathrm{rr}} \operatorname{Brt}\left[\mathrm{Y}^{\mathrm{rs}}\right]= \\
& \mathrm{X}^{\mathrm{t}} \quad \mathrm{B}^{\mathrm{ts}} \quad \mathrm{B}^{\mathrm{tr}} \mathrm{Btt}\left[\mathrm{Y}^{\mathrm{ts}}\right] \\
& {\left[Y^{s s}+Y^{s r}+Y^{s t}\right]+} \\
& {\left[y^{r s}+y^{r r}+Y^{r t}\right]+} \\
& {\left[Y^{t s}+Y^{t r}+Y^{t t}\right]}
\end{aligned}
$$

With $\mathrm{B}^{\mathrm{ss}}$ as the output, we get the classic Leontief inverse matrix. Then, using the right side of eqn. (5), decompose the total production of country $r$ into the following components, which are derived from the difference demand product:

$$
\begin{gathered}
X^{r}=B^{r s} Y^{s s}+B^{r s} Y^{s r}+B^{r s}+Y^{s r}+A^{s r} B^{r s} Y^{s r}+A^{s r} B^{s r} Y^{s t}+A^{s r} B^{r r} Y^{r s}+ \\
+A^{s r} B^{r r} Y^{r r}+A^{s r} B^{r t} Y^{t s}+A^{s r} B^{r t} Y^{r t}
\end{gathered}
$$

In all the intermediate export from country $\mathrm{S}$ to $\mathrm{K}$ is:

$$
Z^{s r}=A^{s r} X^{r}=A^{s r} X^{r r} Y^{r r}+A^{s r} L^{r r} E^{r}
$$

As a result, we utilize VA=DVA+FVA+RDV K to calculate VAT2 at the country level. Based on the work of (X. Yao, W.U.H. Shah, R. Yasmeen, et al 2020) on the super-SBM model development, we assume that there are $\mathrm{N}$ number of decision-making units (DMUs) with three types of variables: inputs, good outputs (desirable), and poor outputs (undesirable) (undesirable). 


\subsection{Measuring Value Added Trade}

According to Balassa (1965), the GVC is a continuous development cycle that occurs in numerous nations, with each country focusing on a distinct stage of production based on its comparative advantage. Despite this, before Hummels et al. submitted their dissertation, a study on vertical specialization was put on hold due to computational issues. To calculate the GVC location, Hummels proposed the quantitative index of systematic measurement and used the input-output framework. Koopman et al. (2011), on the other hand, cited Hummels et al. (2001) and gave a primitive explanation with numerous faults. To begin, Hummels calculated that all intermediate imports were significantly reliant on foreign value-added exports, ignoring intermediate home exports and returning after processing overseas. Furthermore, it was believed that a country could not export intermediate goods while increasing their value. Second, it is assumed that products intended for domestic use and those intended for export use the same importing inputs. The intermediate relationship between imported domestic usage and export processing was plundered as a result of this assumption. The accounting approach established by Wang et al. (2013) accounts for extra data on the domestic value-added structure and double counting in aggregate trade flows that the Leontief norm decomposition missed. We use the WWZ method based on the input-output analysis system for country-to-country comparisons, as recommended by Wang et al. (2013). It also improves the validity of the KWW mechanism, not only for regional aggregate exports but also at a higher level.

\subsection{Model Formulation}

We examined the effect on the energy efficiency of VAT in the global value chain of Asian countries within the Belt and Road. We agreed that trade could be a way to promote energy conservation by transferring technology. Given the role of VAT in the global supply chain and the need for energy conservation, the following model is proposed:

$$
\begin{gathered}
E E_{i t}=\emptyset_{0} \times E E_{i t-1}+\emptyset_{1} \times V A T_{i t}+\emptyset_{2} \times R D_{i t}+\emptyset_{3} \times \text { dummy }_{\text {country }_{i t}}+ \\
\emptyset_{4}+\text { dummy_year }_{i t}+\mu_{i t}
\end{gathered}
$$

$E E_{t}$ is energy efficiency and is expected to be positive towards trade. $V A_{t}$ is value-added export (VAEX), and value-added imports (VAIMP), which are expected to remain positive towards energy efficiency. $D_{t}$ represents the investment in research and development and is predicted to be positive in all models. Dummy country and year are country effects and time effects. Therefore, we expect VAT to be positive towards energy efficiency. To analyze the long-term impact of VAT on energy output, we employed the Generalized Method of Moments (GMM). This approach is suitable since it has a short duration (T) and broad cross-sections (N) (Arellano and Bond, 1991; Khan et al., 2019) GMM has the advantage of accounting for heteroscedasticity, correlation, and endogeneity in panel data.

\section{Empirical Results and Discussion}

We first present descriptive statistics of the impact of Value added Tax on energy efficiency combined with Research and Development of Asian Countries under Belt and Road. From the 
table (1), value added Trade had the highest meaning rating (0.605), successive by Research and Development (0.1136). On average, energy efficiency can be positively impacted by value added trade is $24 \%(0.241)$ with a standard deviation $(0.104)$ and minim value $(0.05730$ and maximum value (0.452).

The results in (1) show that there is a positive but significant correlation between VAT and energy efficiency. With the significance level, the positive association between VAT and energy efficiency is consistent with theoretical expectations. However, research \& development also improve energy efficiency in selected Asian countries with a significant value of (0.1136). The table below provides the summary of the findings,

Table 1. Descriptive Statistics

\begin{tabular}{|l|l|l|l|l|}
\hline & Mean & Std. deviation & Min & Max \\
\hline EE & 0.241 & 0.104 & 0.0573 & .452 \\
\hline VAT & $\mathbf{0 . 4 0 5}$ & 0.0463 & $\mathbf{0 . 6 5 2}$ & 0.894 \\
\hline R\&D & 0.1136 & 0.321 & $\mathbf{0 . 0 1 2}$ & 0.1429 \\
\hline
\end{tabular}

Trade and energy efficiency have a possible reverse causality. In addition, the high energy consumption relating energy efficiency industries trigger endogeneity problems. So, with the established of the simultaneous equation model to avoid biased results, we applied GMM to address the endogeneity problem among the variables.

Table 2. GMM results

\begin{tabular}{|l|l|l|l|}
\hline & EE & EE & EE \\
\hline EE & $0.332 * * *$ & $0.333 * * *$ & 0.152 \\
\hline VAT & 0.0018 & $0.036 * *$ & $0.144 * * *$ \\
\hline R\&D & & 0.0015 & $0.0173 *$ \\
\hline AR (1\&2) & $(-1.45),(0.28)$ & $(-1.46),((0.433)$ & $(-1.41),(0.311)$ \\
\hline
\end{tabular}

Note: the dummy variable for years and time were not shown in the table since they both responded No and Yes for GMM. EE, represents energy efficiency, VAT represent value added Trade and R\&D is research and development. AR (1 and 2) represents the Arabella GMM methods used.

Table 3. Simultaneous Equations with R\&D findings

\begin{tabular}{|l|l|l|l|l|}
\hline Variables & EE & EE & VAT & VAT \\
\hline EE (-1) & $0.332 * * *$ & $0.3133 * * *$ & - & - \\
\hline VAT & $0.0101 * *$ & $0.1059 * * *$ & - & - \\
\hline R\&D & $0.0651 * *$ & $0.068 * *$ & $0.10 * * *$ & $0.2 * * *$ \\
\hline AR (1\&2) & $(-1.67),(0.37)$ & $(-1.69),((0.36)$ & $(-3.77),(-3.28)$ & $(-2.62),(0.10)$ \\
\hline
\end{tabular}

Note: The table provides the results from the estimates from the simultaneous equation with the inclusion of Research and Development of countries. EE, represents energy efficiency, 
VAT represent value added Trade and R\&D is research and development. AR (1 and 2) represents the Arabella GMM methods used.

The results reported in Table (3) further indorsed that VAT significantly promotes energy efficiency, with an impact coefficient of (0.0201). The findings show a significant increase in energy efficiency at the $5 \%$ significance level. After controlling the heterogeneous effects, the magnitude impact of the coefficient has noticeably increased from (0.0101) to (0.1059), which approves that the heterogeneity of countries and years influence the empirical findings of the model. Thus, it is imperative to control the virtual effects of country and years in the estimation. The outcome are consistent with the findings of (X. Yao, W.U.H. Shah, R. Yasmeen, et al, 2020). Further, it validates that trade in the GVC mechanism helps to promote energy efficiency. However, the findings show that, $R \& D$ investment has a positive and significant effect on energy efficiency. The positive influence of $R \& D$ investment in promoting energy efficiency mainly indicates that the industries involved in GVC can build more sophisticated manufacturing equipment and operational methods, thereby improving energy efficiency. In fact, the analysis evident VAT substantially increases energy efficiency. In using the export VAT and import VAT each of which has its own mechanism to influence energy efficiency, value-added export trade enables firms to extend their products globally and accrue economies of scale and thus boosting environmental efficiency. This argument is in line with the attendant literature, for instance, the export-oriented firm can improve environmental performance (Galdeano-Gómez, 2010).

\section{Conclusions and Discussions}

The paper examined the of trade mechanism on energy efficiency in the global value chain of Asian countries within the Belt and Road Initiatives. The sample countries for the study are: Vietnam, Thailand, Singapore, New Zealand, Mongolia, Malaysia, Korea, Rep, Indonesia, China, Cambodia, Brunei Darussalam, Tajikistan, Kyrgyz Republic, Kazakhstan, Azerbaijan, Sri Lanka, Pakistan, Nepal, India, and Bangladesh. We employed simultaneous equation with GMM and SBM model proposed by Huang et al. (2014) to measure the energy efficiency of sampled countries. In fact, after 1990, GVC accelerated the flow of foreign trade, allowing emerging countries to catch up to developed countries. Despite the fact that emerging economic companies play a smaller role in global production than developed countries, the GVC is supposed to be a pathway for developing their economies through trade.

We find VAT significantly improves energy efficiency after controlling the time and country effects. We further also established that energy efficiency also increases the VAT. In addition, we find that exports and imports are two significant mechanisms for energy efficiency improvements. Finally, Technological progress can improve energy efficiency by utilizing cleaner energy resources. Higher-income countries can afford research and development $(\mathrm{R} \& \mathrm{D})$ expenditures and therefore possess the capacity to implement innovative technologies.

Energy efficiency could be greatly promoted by emphasizing its significance in the age of 
GVC. Furthermore, operational policies for the growth of the manufacturing sector and the creation of value chains for emerging industries are urgently required. Special attention must be paid to countries that operate industries with low value-added goods from a global perspective.

\section{References}

Fan, M. Q., Ren, R. E., \& Chen, G. C. (2010). An empirical study on the impacts of technological changes, factor substitution and trade on energy intensity. China Econ, 1, 237-258.

Fang, Z., \& Chang, Y. (2016). Energy, human capital and economic growth in Asia Pacific countries - Evidence from a panel cointegration and causality analysis. Energy Economics, 56, 177-184. https://doi.org/10.1016/j.eneco.2016.03.020

Fisher-Vanden, K., Jefferson, G. H., Liu, H., \& Tao, Q. (2004). What is driving China's decline in energy intensity? Resource and Energy economics, 26(1), 77-97.

https://doi.org/10.1016/j.reseneeco.2003.07.002

Frikha, M. (2018). Income, trade openness and energy interactions: Evidence from simultaneous equation modelling. Energy, 147, 799-811.

https://doi.org/10.1016/j.energy.2018.01.013

Galdeano-Gómez, E. (2010). Exporting and environmental performance: a firm-level productivity analysis. World Economy, 33(1), 60-88.

https://doi.org/10.1111/j.1467-9701.2009.01188.x

Ladu, M. G., \& Meleddu, M. (2014). Is there any relationship between energy and TFP (total factor productivity )? A panel cointegration approach for Italian regions. Energy, 75, 560-567. https://doi.org/10.1016/j.energy.2014.08.018

Li, D. C., Li, J., \& Zhang, D. (2016). Efficiency snakes and energy ladders: A (meta-) frontier demand analysis of electricity consumption efficiency in Chinese households. Energy Policy, 91, 383-396. https://doi.org/10.1016/j.enpol.2016.01.009

Li, K., Chen, W., \& Wang, Y. (2014). Foreign trade, labor market segmentation and human capital investment in China. J. World Econ., 3, 56-79.

Li, Q., Wei, W., \& Xu, K. (2014). Estimation of technological innovation and structural readjustment on the energy consumption rebound effect. China Popul. Res. Env., 24, 64-67.

Melitz, M. J. (2003). The impact of trade on intra-industry reallocations and aggregate industry productivity. Econometric, 71(6), 1695-1725.

https://doi.org/10.1111/1468-0262.00467

Meng, J., Liu, J., Guo, S., Huang, Y., \& Tao, S. (2015). The impact of domestic and foreign trade on energy-related PM emissions in Beijing. Applied Energy, 184, 853-862.

https://doi.org/10.1016/j.apenergy.2015.09.082

Mielnik, O., \& Goldemberg, J. (2002). Foreign direct investment and decoupling between 
energy and gross domestic product in developing countries. Energy policy, 30(2), 87-89. https://doi.org/10.1016/S0301-4215(01)00080-5

Moreau, V., \& Vuille, F. (2018). Decoupling energy use and economic growth: Counter evidence from structural e ff ects and embodied energy in trade. Appl. Energy, 215, 54-62. https://doi.org/10.1016/j.apenergy.2018.01.044

Morrow, J. D., Siverson, R. M., \& Tabares, T. E. (1998). The political determinants of international trade: the major powers, 1907-1990. American political science review, 92(3), 649-661. https://doi.org/10.2307/2585487

Nie, P., Chen, Z., Wang, C., \& Chen, X. (2019). Innovation analysis under trading energy ef fi ciency. Energy, 186, 115866. https://doi.org/10.1016/j.energy.2019.115866

Shah, W. U. H., Yasmeen, R., \& Padda, I. U. H. (2019). An analysis between financial development, institutions, and the environment: a global view. Environ. Sci. Pollut. Res., 26, 21437-21449. https://doi.org/10.1007/s11356-019-05450-1

Sharma, C., \& Mishra, R. K. (2015). International trade and performance of firms: Unraveling export, import and productivity puzzle. The Quarterly Review of Economics and Finance, 57, 61-74. https://doi.org/10.1016/j.qref.2015.02.001

Shu, T., Zhong, X., \& Zhang, S. (2011). TFP Electricity Consumption Efficiency and Influencing Factor Analysis Based on DEA Method. Energy Procedia, 12, 91-97. https://doi.org/10.1016/j.egypro.2011.10.013

Sohag, K., Ara, R., Mastura, S., \& Abdullah, S. (2015). Dynamics of energy use, technological innovation, economic growth and trade openness in Malaysia. Energy, 90(Part 2), 1497-1507. https://doi.org/10.1016/j.energy.2015.06.101

Sun, C., Ma, T., \& Xu, M. (2018). Exploring the prospects of cooperation in the manufacturing industries between India and China : A perspective of embodied energy in India-China trade. Energy Policy, 113, 643-650. https://doi.org/10.1016/j.enpol.2017.11.055

Xie, J., \& Zhou, Z. (2009). Import trade, absorptive capacity and international R\&D technology spillover the study of Chinese provincial panel data. J. World Econ, 9, 68-81.

Xu, B., \& Lin, B. (2018). PT School of Management, China Institute for Studies in Energy Policy, Collaborative. Energy Econ, 74, 733-745. https://doi.org/10.1016/j.eneco.2018.07.024

Yao, X., Yasmeen, R., Li, Y., Hafeez, M., \& Padda, I. U. H. (2019). Free trade agreements and environment for sustainable development: a gravity model analysis. Sustainability, 11(3), 597. https://doi.org/10.3390/su11030597

Yao, Y., Ivanovski, K., Inekwe, J., \& Smyth, R., (2019). Human capital and energy consumption: Evidence from OECD countries. Energy Econ, 84, 104534.

https://doi.org/10.1016/j.eneco.2019.104534 


\section{Copyright Disclaimer}

Copyright for this article is retained by the author(s), with first publication rights granted to the journal.

This is an open-access article distributed under the terms and conditions of the Creative Commons Attribution license (http://creativecommons.org/licenses/by/4.0/). 